Original Article

\title{
ANALYSIS OF THE HUMAN CEPHALOMETRIC PARAMETERS IMPORTANT FOR DENTAL PRACTICE
}

\author{
Stojanka Arsić ${ }^{1}$, Milena Trandafilović1, Sonja Janković ${ }^{2}$, Dragana Ilić ${ }^{2}$, Bojan Nedović ${ }^{3}$, Nikola Vitković ${ }^{4}$, \\ Miloš Stojkovićc ${ }^{4}$, Milica Tufegdžićc ${ }^{5}$, Jelena Mitić ${ }^{4}$, Miroslav Trajanović ${ }^{4}$ \\ ${ }^{1}$ Department of Anatomy, Faculty of Medicine, University of Niš, Niš, Serbia \\ ${ }^{2}$ Radiology Center, Clinical Center Niš, Niš, Serbia \\ ${ }^{3}$ Mental Health Protection Clinic, Clinical Center Niš, Niš, Serbia \\ ${ }^{4}$ Faculty of Mechanical Engineering, University of Niš, Niš, Serbia \\ ${ }^{5}$ College of Applied Mechanical Engineering, Trstenik, Serbia
}

\begin{abstract}
Cephalometry is a measurement of the head by imaging, also taking into account the layer which consists of all the soft tissues of the head. Following the introduction of computed tomography $(C T), 3 D$ reconstruction of the head and neck structures and 3D analysis of angular and linear cephalometric parameters was enabled. This study aimed to determine the characteristic cephalometric parameters, using the $2 D$ reconstruction of the multi-slice CT (MSCT) images, which are essential for computer designing of the parametric-geometric-mathematical model (PGMM) of the human skull. We conducted the study on 20 CT scans of adult patients (12 males and 8 females), taken from the radiology archive of the Clinical Center in Niš. Measurements were done on $2 D$ reconstruction images of preselected $3 D$ images of the human head created using MSCT. The values of 29 linear cephalometric parameters (LCP) and 20 angular cephalometric parameters $(A C P)$ were determined. Statistically significant differences between males and females were noted for the distance between the points Sella and Supraorbitale and for the distance between the points Subspinale and Labium superius. Mean values of cephalometric parameters obtained by measurements on $2 D C T$ images can be used to generate normative parameters which represent values used to generate 3D PGMM of the human skull. This PGMM of the skull may allow a more accurate diagnosis, better selection of treatment methods and more accurate prognosis for healing in orthodontics, implantology, oral and maxillofacial surgery.
\end{abstract}

Key words: cephalometric parameters, computed tomography, 3D modeling.

\section{Introduction}

Cephalometry means measurements on the head, taking into account the cover that builds all the soft tissue of the head, regardless of whether these measurements are performed on a live patient or a cadaveric material. The basic principles for obtaining a valid profile radiographic image were made by Pacinni in 1922 as cited by Broadbent [1]. The beginning of the application of this method is related to 1931 when Broadbent [1] introduced a cephalostat in the technique for recording the head profile, a device by which the recording can be done from the same projection with greater certainty, because the head could always be placed almost in the same position relative to anode and film.

Radiography made by the help of digital X-ray machines dramatically facilitated the clinical approach to the cephalometric analysis. The advantages of this method are reflected in the storage, transmission, improvement of image quality, reduced patient radiation, and the ability to analyze cephalometric parameters us-

Correspondence to: Stojanka Arsić, M.D., Ph.D.

Faculty of Medicine, 81 Zoran Đinđić Blvd., 18000 Niš, Serbia

Phone: +381641703100

E-mail: stojanka.arsic@gmail.com

Received September 12 $2^{\text {th }}, 2018 /$ Accepted April 18 ${ }^{\text {th }}, 2019$ ing a computer [2]. Digital radiography also provides better visualization of the soft tissue structures. However, the disadvantages of these methods, classical and digital 2D radiography, may also be the inability to identify cephalometric points due to the superposition of the bone structures as well as reporting radiographic magnification and rotation of the head in the cephalostat [3].

After the introduction of 3D reconstruction of the head and neck with the help of computerized tomography (CT), 3D analysis enabled more precise diagnostics in the field of maxillofacial surgery, orthodontics and implantology. On the same CT image, 2D reconstruction can be made at any level, and the researcher can choose which plane he will use as a plane of the crosssection and in this way simulate the profile cephalometric image (virtual cephalogram) without re-radiating the patient. Also, the position of the patient's head doesn't need to be strictly defined (eliminates the use of cephalostat) during radiography because there is the possibility of rotating a 3D image on a computer [4].

The study aimed to determine the characteristic cephalometric parameters using the $2 \mathrm{D}$ reconstruction of multi-slice computed tomography (MSCT) recordings that are significant for the computer construction of the parametric-geometric-mathematical model (PGMM) of the human skull. 


\section{Material and Methods}

We performed morphometry on $20 \mathrm{CT}$ images of adult patients (12 male and 8 female) of the average age of $61 \pm$ 12.76 years, obtained from the archives of the Radiology Center, Clinical Center Niš. The Institutional Review Boards at Clinical Center Niš approved all procedures according to the Declaration of Helsinki. We selected the subjects by a random method and the only criterion for selection was the absence of defects, fractures, and pathological processes on the bones of neurocranium and viscerocranium and on the surrounding soft tissues.

Measurements were performed on 2D reconstructions previously selected 3D images of the human heads performed on the 64-slice CT or MSCT (Aquillion 64, Toshiba, Japan) according to a standard recording protocol: $120 \mathrm{kVp}, 150 \mathrm{~mA}$, rotational time $0.5 \mathrm{~s}$, cross-section thickness $0.5 \mathrm{~mm}$. As a plane of cross sections for $2 \mathrm{D}$ reconstructions, a mediosagittal plane that passed through the middle of the mandibular symphysis and which is at right angles crossed the coronal plane that passed through the points of the mandibular angles was taken.

The values of 29 linear cephalometric parameters (LCP) and 20 angular cephalometric parameters (ACP) were determined by using the previously defined cephalometric points (Table 1; Figure 1). The values of these 49 parameters were used to evaluate the shape, size, and position of the three craniofacial complexes: (1) the cranial base, (2) the middle of the face, (3) the mandible (Tables 2 and 3; Figures 2 and 3). For further analysis, the values of 7 parameters were added as the cephalometric points on the soft tissues.

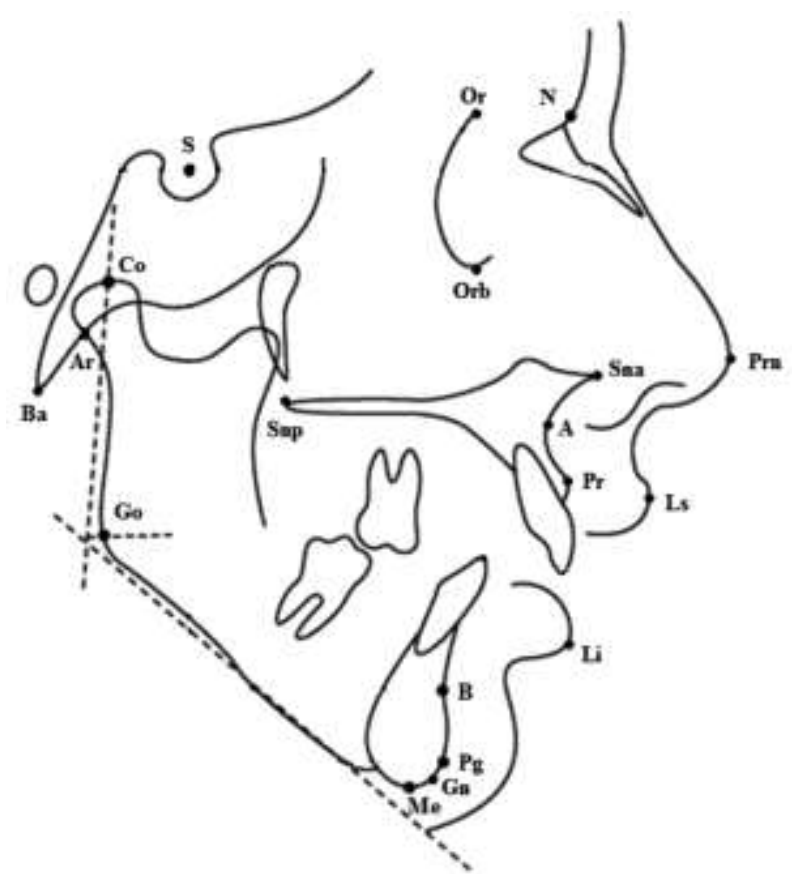

Fig. 1 Schematic representation of the topographic cephalometric points from Table 1 on the human profile image - A, Ar, B, Ba, Cd, Go, Gn, IOrb, Li, Ls, Me, N, Pg, Prn, Pr, S, Sna, Snp, Sorb.
Table 1 Topographic cephalometric points characteristic for the profile image of the human head

\begin{tabular}{ll}
\hline $\begin{array}{l}\text { Cephalometric } \\
\text { point }\end{array}$ & Definition \\
\hline Articulare (Ar) & $\begin{array}{l}\text { The section of the mandibular head with } \\
\text { the shadow of the external, exocranial } \\
\text { surface of the basilar part of the occipital } \\
\text { bone } \\
\text { The lowest point of the basilar part of the } \\
\text { occipital bone located on the anterior mar- } \\
\text { gin of the foramen magnum, at the medial } \\
\text { plane; on the profile image, it is seen as the } \\
\text { lowest point on the profile shadow of the } \\
\text { occipital bone }\end{array}$
\end{tabular}

Condylion (Cd) The highest point of the mandibular head on the condylar process

Gonion (Go) The point where the symmetry of the angle between the tangents of the inferior margin of the mandibular body and the posterior margin of the mandibular ramus cut mandibular contour at the level of the mandibular angle

Gnathion $(\mathrm{Gn})$ The point at which the symmetric line of the angle that build the tangents at the lower edge of the mandible and the extended plane Nasion-Pogonion, cut the outer edge of the shadow of the beard; it is located between the points Pogonion and Menton

Infraorbitale The most inferior point on the inferior (IOrb) margin of the aditus orbitae

Labrale inferius The most prominent point of the inferior (Li) lip

Labrale The most prominent point of the superior superius (Ls) lip

Menton (Me) The lowest point of the shadow of the beard, in which the shadow of the beard and the shadow of the inferior margin of the mandible are joined

Nasion $(\mathrm{N}) \quad$ The connection between the internasal and nasofrontal suture; on the profile image, it is the most anterior point of the nasofrontal suture

Pogonion $(\mathrm{Pg}) \quad$ The most prominent point of the beard profile

Pronasale (Prn) The most prominent point of the nose

Prosthion (Pr) The lowest point on the profile of the maxillary alveolar process at the level of the incisors

Sella (S) The middle of the contour of the sella turcica on the profile image of the head

Spina nasalis The apex of the anterior nasal spine anterior (Sna)

Spina nasalis The apex of the posterior nasal spine posterior (Snp)

Subspinale (A) The point on the deepest part on the concave profile of the alveolar process of the mandible

Supramentale The deepest point of the concave profile of (B) the chin

Supraorbitale The highest point on the superior margin (SOrb) of the aditus orbitae 
Table 2 The names and definitions of the linear cephalometric parameters

\begin{tabular}{|c|c|c|}
\hline \multirow[t]{2}{*}{ No } & \multirow[t]{2}{*}{ Name } & Definition \\
\hline & & Cranial measurements \\
\hline 1 & S-N & The distance between Sella and Nasion points; a cranial base in a mediosagittal plane \\
\hline 2 & S-Ar & The distance between the points Sella and Articulare \\
\hline 3 & $\mathrm{~N}-\mathrm{Ba}$ & $\begin{array}{l}\text { The distance between the points Nasion and Basion represents a cranial base in a mediosagittal plane } \\
\text { (Ricketts analysis) }\end{array}$ \\
\hline 4 & $\mathrm{~S}-\mathrm{Ba}$ & The distance between the points Sella and Basion \\
\hline \multirow[t]{2}{*}{5} & S-SOrb & The distance between the points Sella and Supraorbitale \\
\hline & & The middle of the face \\
\hline 6 & S-Go & The distance between the points Sella and Gonion \\
\hline 7 & $\mathrm{~N}-\mathrm{A}$ & $\begin{array}{l}\text { The distance between the points Sella and Subspinale; sagittal referent plane anterior-posterior position of } \\
\text { the maxilla in the Steiner plane }\end{array}$ \\
\hline 8 & S-Gn & The distance between the points Sella and Gnathion \\
\hline 9 & $\mathrm{~N}-\mathrm{Pg}$ & The distance between the points Nasion and Pogonion \\
\hline 10 & N-Sna & The distance between the points Nasion and Spina nasalis anterior \\
\hline 11 & $\mathrm{~N}-\mathrm{Pr}$ & The distance between the points Nasion and Prosthion \\
\hline 12 & S-Snp & The distance between the points Sella and Spina nasalis posterior \\
\hline 13 & S-Pr & The distance between the points Sella and Prosthion \\
\hline 14 & Snp-Pr & The distance between the points Spina nasalis posterior and Prosthion \\
\hline \multirow[t]{2}{*}{15} & S-IOrb & The distance between the points Sella and the most inferior point on the inferior margin of the aditus orbitae \\
\hline & & The mandible \\
\hline 16 & Ar-Go & The distance between the points Articulare and Gonion \\
\hline 17 & Go-Gn & The distance between the points Gonion and Gnathion; the mandibular plane in the Steiner analysis \\
\hline 18 & Go-Me & The distance between the points Gonion and Menton; the mandibular plane \\
\hline 19 & $\mathrm{~N}-\mathrm{Me}$ & The distance between the points Nasion and Menton; total face height \\
\hline 20 & N-B & $\begin{array}{l}\text { The distance between the points Nasion and Supramentale; an anterior-posterior position of the mandible in } \\
\text { the Steiner analysis }\end{array}$ \\
\hline 21 & Me-Sna & The distance between the points Menton and Spina nasalis posterior \\
\hline 22 & Co-Gn & The distance between the points Condylion and Gnathion \\
\hline 23 & Co-Go & The distance between the points Condylion and Gonion; posterior or facial height \\
\hline \multirow[t]{2}{*}{24} & Go-Pg & The distance between the points Gonion and Pogonion; the length of the mandibular body \\
\hline & & Soft-tissue measurements \\
\hline 25 & Prn-(N-Pg) & The distance between the points Pronasale and line between the points Nasion and Pogonion \\
\hline 26 & A-Ls & The distance between the points Subspinale and Labium superius \\
\hline 27 & Li-Pg & The distance between the points Labium inferius and Pogonion \\
\hline 28 & Ls-(N-Pg) & The distance between the points Labium superius and line between the points Nasion and Pogonion \\
\hline 29 & Li-(N-Pg) & The distance between the points Labium inferius and the line between the points Nasion and Pogonion \\
\hline
\end{tabular}

Table 3 Names and definitions of angular cephalometric parameters

\begin{tabular}{|c|c|c|}
\hline No & Name & Definition \\
\hline & & Cranial measurements \\
\hline 1 & $\mathrm{~N}-\mathrm{S}-\mathrm{Ar}$ & The angle between the points Nasion-Sella-Articulare \\
\hline 2 & $\mathrm{Ba}-\mathrm{S}-\mathrm{Or}$ & The angle between the points Basion-Sella-Orbitale \\
\hline \multirow[t]{2}{*}{3} & $\mathrm{Ba}-\mathrm{S}-\mathrm{N}$ & The angle between the points Basion-Sella-Nasion \\
\hline & & The middle of the face \\
\hline 4 & S-N-A & The angle between the points Sella-Nasion-Subspinale \\
\hline 5 & SOrb-Pr-Snp & The angle between the points Supraorbitale-Prosthion-Spina nasalis posterior \\
\hline 6 & S-SOrb-Pr & The angle between the points Sella-Supraorbitale-Prosthion \\
\hline \multirow[t]{2}{*}{7} & A-N-B & The angle between the points Subspinale-Nasion-Supramentale \\
\hline & & Mandible \\
\hline 8 & S-N-B & The angle between the points Sella-Nasion-Supramentale \\
\hline 9 & N-S-Gn & The angle between the points Nasion-Sella-Gnathion \\
\hline 10 & $\mathrm{SN}<\mathrm{GoGn}$ & The angle between the line Sella-Nasion and Gonion-Gnathion \\
\hline 11 & S-Ar-Go & The angle between the points Sella-Articulare-Gonion \\
\hline 12 & Ar-Go-Me & The angle between the points Articulare-Gonion-Menton \\
\hline 13 & Ar-Go-N & The angle between the points Articulare-Gonion-Nasion \\
\hline 14 & N-Go-Me & The angle between the points Nasion-Gonion-Menton \\
\hline 15 & $\mathrm{SN}<\mathrm{GoM}$ & The angle between the line Sella-Nasion and Gonion-Menton \\
\hline 16 & S-N-Pg & The angle between the points Sella-Nasion-Pogonion \\
\hline 17 & Co-Go-Me & The angle between the points Condylion-Gonion-Menton \\
\hline \multirow[t]{2}{*}{18} & $\mathrm{~N}-\mathrm{A}-\mathrm{Pg}$ & The angle between the points Nasion-Subspinale-Pogonion \\
\hline & & Soft-tissue measurements \\
\hline 19 & Li-Go-Me & The angle between the points Labium inferius-Gonion-Menton \\
\hline 20 & Prn-A-Ls & The angle between the points Pronasale-Subspinale-Labium superius \\
\hline
\end{tabular}

$<$, angle between two lines; -, angle between the points 

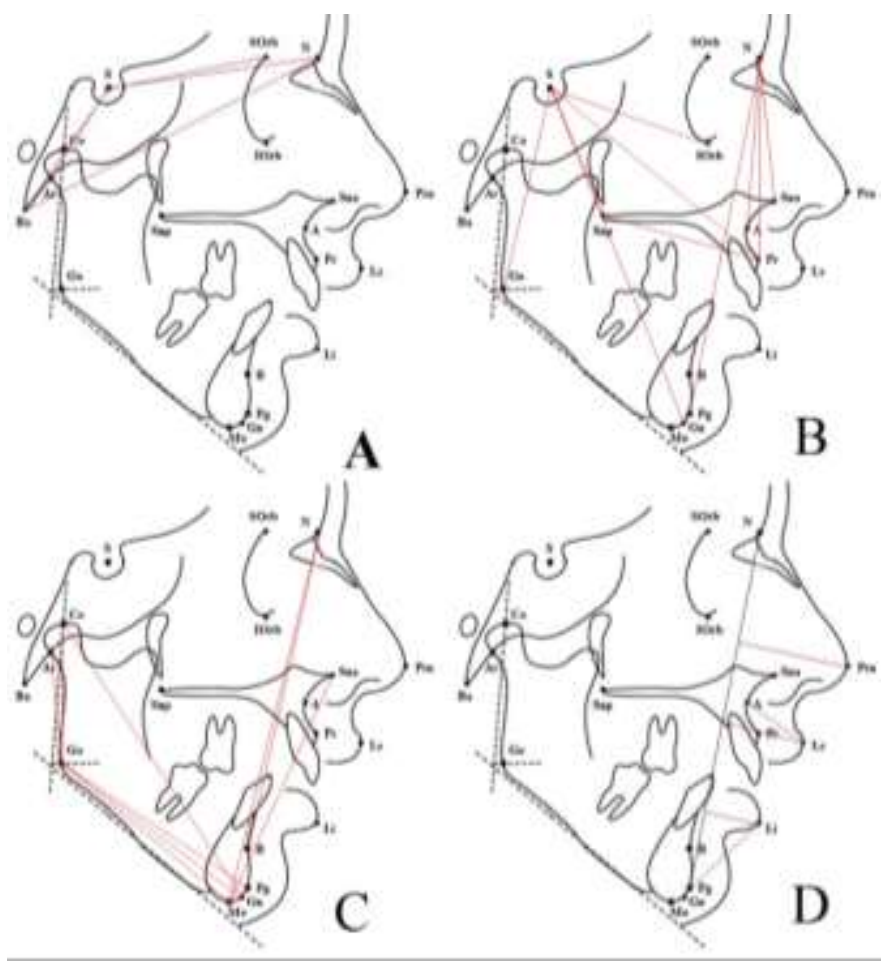

Fig. 2 Schematic representation of linear cephalometric parameters from Table 2 on the human profile image - (A) LCP cranial measurements: S-N; S-Ar; N-Ba; S-Ba; S-SOrb; (B) LCP in the middle of the face: S-Go; N-A; S-Gn; N-Pg; N-Sna; N-Pr; S-Snp; S-Pr; Snp-Pr; S-IOrb (C) LCP of the mandible: Ar-Go; Go-Gn; Go-Me; N-Me; N-B; Me-Sna; Co-Gn; Co-Go; Go-Pg; (D) LCP of the soft tissue: Prn-(N-Pg); A-Ls; Li-Pg; Ls-(N-Pg); Li-(N-Pg).
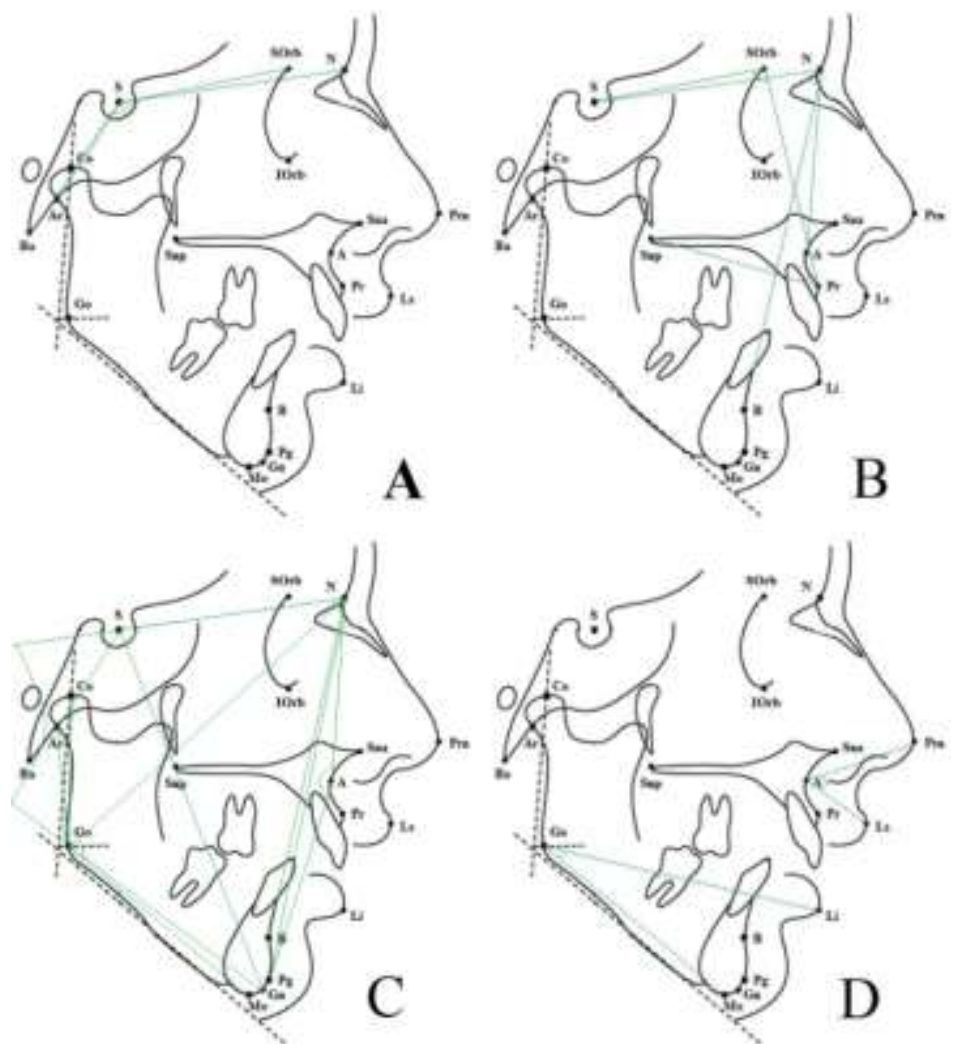

Fig. 3 Schematic representation of angular cephalometric parameters from Table 3 on a human profile image - (A) ACP cranial measurements: N-S-Ar; Ba-S-Or; Ba-S-N; (B) ACP in the middle of the face: S-N-A; SOrb-Pr-Snp; S-SOrb-Pr; A-N-B; (C) ACP of the mandible: S-N-B; N-S-Gn; SN<GoGn; S-Ar-Go; Ar-Go-Me; Ar-Go-N; N-Go-Me; SN<GoM; S-N-Pg; Co-Go-Me; N-A-Pg; (D) Soft-tissue measurements: Li-Go-Me; Prn-A-Ls. 


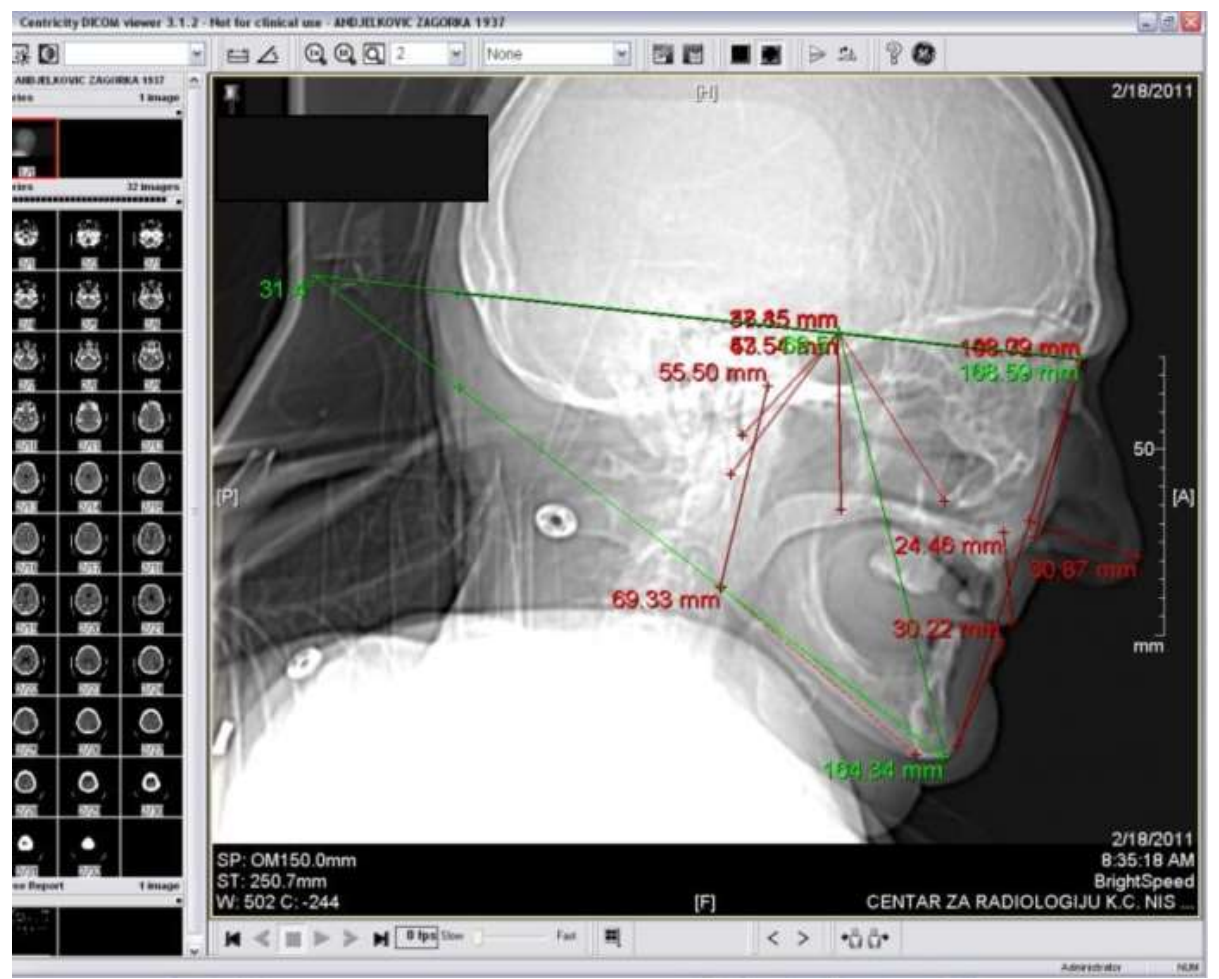

Fig. 4 Measurement of the linear and angular cephalometric parameters in Centricity DICOM viewer window

The measurement of LCP and ACP was performed by manually drawing the measuring lines between previously defined and identified cephalometric points on 2D reconstructions by three researchers, three times for each of the cephalometric parameters, at a time interval of 24 hours, by the Centricity DICOM Viewer program, version 3.12. (Figure 4).

The LCP values are in millimeters ( $\mathrm{mm}$ ) and for ACP in degrees. Statistical significance between male and female groups was defined as a two-sided $p$ value of 0.05 for all analyses, which were carried out using the STATA software package v15.1 (Stata Corporation, College 162 Station, Texas).

\section{Results}

We included 20 subjects (12 male and 8 female) with a mean age of $61 \pm 12.76$ years in this study. The sample was $100 \%$ Caucasian. There were no significant differences between males and females regarding age. The mean values and standard deviations M(SD) of the LCP and ACP are shown in Tables 4 and 5, respectively. An independentsamples t-test reported significant differences between males and females for the distance between the points Sella and Supraorbitale and for the distance between the points Subspinale and Labrale superius.
Table 4 The linear cephalometric parameters in males and females

\begin{tabular}{|c|c|c|c|c|c|}
\hline No & $\begin{array}{l}\text { Abbrevia- } \\
\text { tion }\end{array}$ & $\begin{array}{l}\text { Male N=12 } \\
M(\text { SD) }\end{array}$ & $\begin{array}{l}\text { Female } N=8 \\
M(S D)\end{array}$ & $\mathrm{t}$ & $\mathrm{p}$ \\
\hline 1 & S-N & $65.94(8.81)$ & $64.65(2.37)$ & 0.09 & .929 \\
\hline 2 & S-Ar & $44.94(10.45)$ & $47.93(9.07)$ & 0.66 & .518 \\
\hline 3 & $\mathrm{~N}-\mathrm{Ba}$ & $101.09(13.69)$ & 99.94 (6.53) & 0.22 & .828 \\
\hline 4 & S-Ba & $58.81(21.62)$ & $52.66(9.05)$ & 0.76 & .459 \\
\hline 5 & S-SOrb & $47.57(7.17)$ & $37.19(13.58)$ & 2.24 & .038 \\
\hline 6 & S-Go & $79.19(16.31)$ & $78.45(6.30)$ & 0.12 & .905 \\
\hline 7 & $\mathrm{~N}-\mathrm{A}$ & $54.92(10.46)$ & $56.28(6.31)$ & 0.33 & .746 \\
\hline 8 & S-Gn & $118.75(23.17)$ & $117.63(4.49)$ & 0.13 & .895 \\
\hline 9 & $\mathrm{~N}-\mathrm{Pg}$ & $111.15(19.23)$ & $107.47(10.56)$ & 0.49 & .629 \\
\hline 10 & N-Sna & $51.77(10.91)$ & $48.98(4.55)$ & 0.68 & .505 \\
\hline 11 & N-Pr & $62.39(13.72)$ & $66.10(9.02)$ & 0.67 & .511 \\
\hline 12 & S-Snp & $43.65(9.53)$ & $46.00(3.01)$ & 0.67 & .511 \\
\hline 13 & S-Pr & $83.92(16.46)$ & 84.64 (7.34) & 0.12 & 909 \\
\hline 14 & Snp-Pr & $50.28(9.48)$ & $47.76(5.90)$ & 0.68 & .502 \\
\hline 15 & S-IOrb & 50.35 (9.99) & $44.52(4.71)$ & 1.53 & .143 \\
\hline 16 & Ar-Go & $37.00(8.54)$ & $32.51(8.59)$ & 1.15 & .265 \\
\hline 17 & Go-Gn & 71.58(16.07) & $72.04(5.34)$ & 0.08 & .939 \\
\hline 18 & Go-Me & $68.53(15.54)$ & $67.77(4.62)$ & 0.13 & .895 \\
\hline 19 & $\mathrm{~N}-\mathrm{Me}$ & $115.91(19.45)$ & $111.78(9.02)$ & 0.56 & .583 \\
\hline 20 & N-B & $95.50(15.76)$ & $91.86(7.97)$ & 0.60 & .556 \\
\hline 21 & Me-Sna & $67.60(10.21)$ & $64.84(6.07)$ & 0.68 & .502 \\
\hline 22 & Co-Gn & $107.34(20.42)$ & $103.57(11.88)$ & 0.47 & .644 \\
\hline 23 & Co-Go & $56.77(10.23)$ & $56.89(5.02)$ & 0.03 & .976 \\
\hline 24 & Go-Pg & $72.21(15.53)$ & $71.85(4.84)$ & 0.06 & .950 \\
\hline 25 & Prn-(N-Pg) & $36.24(6.34)$ & $31.72(3.98)$ & 1.79 & .090 \\
\hline 26 & A-Ls & $22.50(4.94)$ & $17.90(4.05)$ & 2.18 & .042 \\
\hline 27 & $\mathrm{Li}-\mathrm{Pg}$ & $34.58(12.77)$ & 30.08 (3.18) & 0.97 & .345 \\
\hline 28 & Ls-(N-Pg) & $15.91(4.59)$ & $11.14(6.73)$ & 1.89 & .075 \\
\hline 29 & Li-(N-Pg) & $14.97(5.63)$ & $11.48(5.53)$ & 1.37 & .188 \\
\hline
\end{tabular}


Table 5 Angular cephalometric parameters in males and females

\begin{tabular}{|c|c|c|c|c|}
\hline No Abbreviation & $\begin{array}{c}\text { Male } \\
\mathrm{N}=12 \\
\mathrm{M}(\mathrm{SD})\end{array}$ & $\begin{array}{c}\text { Female } \\
\mathrm{N}=8 \\
\mathrm{M}(\mathrm{SD})\end{array}$ & $\mathrm{t}$ & $\mathrm{p}$ \\
\hline \multicolumn{5}{|c|}{ Cranial measurements } \\
\hline $1 \quad \mathrm{~N}-\mathrm{S}-\mathrm{Ar}$ & $117.67(17.01)$ & $114.67(6.61)$ & 0.47 & .642 \\
\hline Ba-S-Or & $125.50(13.66)$ & $121.09(7.11)$ & 0.84 & .414 \\
\hline Ba-S-N & $120.15(14.88)$ & $116.74(5.91)$ & 0.61 & .548 \\
\hline \multicolumn{5}{|c|}{ The middle of the face } \\
\hline 4 S-N-A & $77.32(9.98)$ & $75.19(13.27)$ & 0.41 & .686 \\
\hline Or-Pr-Snp & $59.64(3.64)$ & 74.97(36.97) & 1.45 & .165 \\
\hline S-Or-Pr & $92.42(6.87)$ & $86.17(16.95)$ & 1.15 & .263 \\
\hline A-N-B & $6.27(4.67)$ & $4.39(3.12)$ & 0.99 & .332 \\
\hline \multicolumn{5}{|l|}{ Mandible } \\
\hline 8 S-N-B & 77.56 (6.13) & 77.69 (4.73) & 0.051 & .960 \\
\hline N-S-Gn & 74.21(15.91) & $71.39(8.25)$ & 0.46 & .652 \\
\hline $\mathrm{SN}<\mathrm{GoGn}$ & $31.45(12.79)$ & $29.11(9.19)$ & 0.44 & .662 \\
\hline S-Ar-Go & $152.88(14.58) 1$ & 155.01(11.37) & 0.35 & .732 \\
\hline Ar-Go-Me & $120.50(11.05) 1$ & $120.46(8.04)$ & 0.01 & .993 \\
\hline Ar-Go-N & $73.75(36.30)$ & $56.11(23.04)$ & 1.21 & .240 \\
\hline N-Go-Me & $73.88(6.57)$ & $66.31(16.11)$ & 1.47 & .159 \\
\hline $\mathrm{SN}<\mathrm{GoMe}$ & $33.55(12.73)$ & $40.41(25.91)$ & 0.79 & .439 \\
\hline $\mathrm{S}-\mathrm{N}-\mathrm{Pg}$ & $77.55(8.54)$ & $79.91(4.80)$ & 0.70 & .488 \\
\hline Co-Go-Me & $115.82(8.38) \quad 1$ & $118.66(9.83)$ & 0.69 & .497 \\
\hline $18 \quad \mathrm{~N}-\mathrm{A}-\mathrm{Pg}$ & $170.13(6.54) 1$ & $170.07(6.97)$ & 0.02 & .987 \\
\hline \multicolumn{5}{|c|}{ Soft-tissue measurements } \\
\hline 19. Li-Go-Me & $27.31(3.94)$ & $28.43(3.72)$ & 0.64 & .532 \\
\hline 20. Prn-A-Ls & 70.74(11.66) & $77.34(12.65)$ & 1.20 & .250 \\
\hline
\end{tabular}

\section{Discussion}

Creating the 3D PGMM of the skull is a complex process that is used today in dentistry, primarily in the modern diagnostics and preoperative planning. For generating of 3D models of physical objects, different computer-aided design (CAD) techniques are used. In the field of reverse engineering, various techniques are applied to the scanned models that originate from a physical model (bones or skull in the whole), with the aim to create a satisfactory CAD model. The process of creating a CAD model can be a complicated or straight forward procedure, which depends on the complexity of the physical model. The final product of this process is a valid 3D PGMM [5].

In our investigation, the cephalometric parameters that can be used for the creation of 3D PGMM of the skull were measured, and we propose a more comprehensive list of 49 cephalometric parameters. Such generated PGMM of the skull could have different applications in medicine and technology. PGMM of the skull can be used for the creation of a real 3D bone model with the purpose of studying the effects of different loads on the bone model of the skull. Also, the PGMM of the skull can also be used for the analysis of the different implants in oral and maxillofacial surgery. We point out that, this model can be used for personalized implant production using Additive Manufacturing. The measurement of the cephalometric parameters on the profile CT images provides new opportunities in the research and clinical work in dentistry.
With the help of the study of the X-ray images series, many of the cephalometric characteristics of people in different parts of the world have been found, as well as the specificity of these parameters depending on the age and gender [6-8], so measuring the cephalometric parameters in our population is an essential morphometric procedure for determining the standard values of that population.

This study measured characteristic cephalometric parameters using the $2 \mathrm{D}$ reconstruction of MSCT recordings that are significant for the CAD of the PGMM of the human skull. We report no significant differences between males and females for all LCP and APC except for the distance between the points Sella and Supraorbitale and for the distance between the points Subspinale and Labrale superius. The both LCP were larger in males. There is a few studies with cephalometric analysis between genders. Among Filipinos, the male group had a longer anterior cranial base, total facial height, longer lower anterior facial height, longer ramus height, longer lower posterior dentoalveolar height, and total mandibular length. Statistical significance for these differences was not noted only in the group defined by 9.5 years of age [7]. During cephalometric analysis of Slovenians in the period of the mixed dentition (6 to 14 years of age), significant differences between genders were found only for anterior and posterior face height, with boys showing larger values [8]. In these studies, the most LCP and ACP were defined as well as in our study.

Cephalometric parameters of the patient may also be compared with the established population norms to confirm the diagnosis of dentofacial malocclusion or deformities [9]. A long-lasting untreated malocclusion, such as skeletal open-bite, deep-bite and unilateral open-bite, can lead to the symptoms and signs associated with the dysfunction of the temporomandibular joint [10]. Therapy of this condition involves the use of orthodontics that can lead to unwanted effects in the form of tooth and jaw movement, which is also referred to as an increase of S$\mathrm{N}-\mathrm{A}$ angle. It shows the anteroposterior position of point A (Subspinale) to the base of the skull, as so as it speaks of the sagittal position of the viscerocranium to the neurocranium [11]. Also, the analysis of the craniofacial parameters in patients with Marfan's or fetal alcohol syndrome is the most critical characteristic of these diseases [12-14]. Postoperatively, in the surgical treatment of craniomaxillofacial disorders, deformities, and facial asymmetries, it is essential to monitor the clinical condition, facial condition and conduct the cephalometric analysis [15-18].

Many studies have focused on the reliability of digital methods so that the measurements obtained by these methods are compared with classical methods of measurement [19-22]. Studies have shown that the values of digitally measured cephalometric parameters do not differ, or are more precise, from manually measured values [4]. Also, due to the higher speed of measurement, priority is given to the measurement on the digital imaging $[2,20,21]$. 


\section{Conclusion}

The mean values of the cephalometric parameters obtained by measuring on 2D CT images can be used for obtaining the normative parameters which will be used as input set for the creation of a 3D PGMM of the human skull. PGMMs of the human skull generated in our study provide better conditions for a correct diagnostic, more valid choice of treatment and better prognosis of healing

\section{References}

1. Broadbent BH. A new X-ray technique and its application to orthodontia. Angle Orthod 1931; 1:45-46.

2. Chen SK, Chen YJ, Yao CC, Chang HF. Enhanced speed and precision of measurement in a computer-assisted digital cephalometric analysis system. Angle Orthod 2004; 74:501-507.

3. Kragskov J, Bosch C, Gyldensted C, Sindet-Pedersen S. Comparison of the reliability of craniofacial anatomic landmarks based on cephalometric radiographs and three-dimensional CT scans. Cleft Palate Craniofac J 1997; 34:111-116.

4. Moshiri M, Scarfe WC, Hilgers ML, Scheetz JP, Silveira AM, Farman AG. Accuracy of linear measurements from imaging plate and lateral cephalometric images derived from cone-beam computed tomography. Am J Orthod Dentofacial Orthop 2007; 132: $550-560$.

5. Vitković N, Mitić J, Manić M, et al. The parametric model of the human mandible coronoid process created by method of anatomical features. Comput Math Methods Med 2015. https://www.hindawi. com/journals/cmmm/2015/574132/

6. Kuramae M, Magnani MB, Boeck EM, Lucato AS. Jarabak 's cephalometric analysis of Brazilian black patients. Braz Dent J 2007; 18:258-262.

7. Moldez MA, Sato K, Sugawara J, Mitani H. Linear and angular Filipino cephalometric norms according to age and sex. Angle Orthod 2006; 76:800-805.

8. Drevensek M, Farcnik F, Vidmar G. Cephalometric standards for Slovenians in the mixed dentition period. Eur J Orthod 2006; 28:51-57.

9. Alimere HC, Thomazinho A, de Felício CM. Anterior open bite: a formula for the differential diagnosis. Pro Fono 2005; 17:367-374.

10. Dodić S, Vukadinović M, Sinobad V. Roentgencraniometric analysis of the angular craniofacial dimensions in subjects with temporomandibular disorders. Srp Arh Celok Lek 2007; 135:269-274.

11. Ozerović B. Rendgen craniometry and rendgen cephalometry. 2st ed. Belgrade: Medicinska Knjiga; 1984. (Serbian)

12. Naidoo S, Harris A, Swanevelder S, Lombard C. Foetal alcohol syndrome: a cephalometric analysis of patients and controls. Eur J Orthod 2006; 28:254-261. in orthodontics, implantology, oral and maxillofacial surgery.

Acknowledgment: This paper is part of project III41017 Virtual human osteoarticular system and its application in preclinical and clinical practice, funded by the Ministry of Education and Science of Republic of Serbia, for the period of 2011-2019.

13. Cistulli PA, Gotsopoulos H, Sullivan CE. Relationship between craniofacial abnormalities and sleep-disordered breathing in Marfan's syndrome. Chest 2001; 120:1455-1460.

14. Astley SJ, Magnuson SI, Omnell LM, Clarren SK. Fetal alcohol syndrome: changes in craniofacial form with age, cognition, and timing of ethanol exposure in the macaque. Teratology 1999; 59:163-172.

15. Prinsell JR. Maxillomandibular advancement surgery in a sitespecific treatment approach for obstructive sleep apnea in 50 consecutive patients. Chest 1999; 116:1519-1529.

16. Queiroz TP, Gulinelli JL, Souza FA, et al. Assessment of the accuracy of cephalometric prediction tracings in patients subjected to orthognathic surgery in the mandible. Dental Press J Orthod 2010; 15:117-123.

17. Rooppakhun S, Surasith P, Vatanapatimakul N, Kaewprom Y, Sitthiseripratip K. Craniometric study of Thai skull based on threedimensional computed tomography (CT) data. J Med Assoc Thai 2010; 93:90-98.

18. Dempsey JA, Skatrud JB, Jacques AJ, et al. Anatomic determinants of sleep-disordered breathing across the spectrum of clinical and nonclinical male subjects. Chest 2002; 122:840-851.

19. Arsić S, Perić P, Stojković M, Ilić D, Stojanović M, Ajduković Z, Vučić S. Comparative analysis of linear morphometric parameters of the humane mandibula obtained by direct and indirect measurement. Vojnosanit Pregl 2010; 67:839-846.

20. Celik E, Polat-Ozsoy O, Toygar Memikoglu TU. Comparison of cephalometric measurements with digital versus conventional cephalometric analysis. Eur J Orthod 2009; 31:241-246.

21. Cattaneo PM, Bloch CB, Calmar D, Hjortshøj M, Melsen B. Comparison between conventional and cone-beam computed tomography-generated cephalograms. Am J Orthod Dentofacial Orthop 2008; 134:798-802.

22. Qamaruddin I, Alam MK, Shahid F, Tanveer S, Umer, Amin E. Comparison of popular sagittal cephalometric analyses for validity and reliability. Saudi Dent J 2018; 30:43-46. 